\title{
PINTAR LAS FUERZAS: LA ESCRITURA DE AGUA VIVA
}

\author{
Gustavo Quintero*
}

\section{RESUMEN}

En este artículo consideramos una serie de técnicas utilizadas por Clarice Lispector en su novela Agua viva que la hacen aproximarse a lo que Deleuze denominó una lógica de la sensación, una lógica que la acerca al mundo de la pintura en lugar de a una escritura tradicional. También discutimos cómo por medio de lo que Lispector llamó la entrelínea o un proceso de sugestión se forma una serie de ritmos internos a la narración. Ulteriormente analizamos una serie de imágenes y temas centrales en la novela que hacen de la escritura de Lispector un pintar las fuerzas, un hacer visible.

Palabras claves: Palabras claves: Clarice Lispector, Gilles Deleuze, Literatura brasileña, Agua viva, Pintura.

\section{PAINTING FORCES: THE WRITING OF $A G U A$ VIVA}

\begin{abstract}
In this article we take into account a series of techniques used by Clarice Lispector in her novel Agua viva that approximate her towards what Deleuze designated a logic of sensation, a logic that brings her closer to the world of painting instead of that of a traditional way of writing. We also discuss how, by way of what Lispector called la entrelinea or a process of suggestion, a series of rhythms internal to the narration are formed. Subsequently, we analyze a series of images and central themes within the novel that make Lispector's writing a painting of forces, a making visible.
\end{abstract}

Key words: Clarice Lispector, Gilles Deleuze, Brazilian Literature, Agua Viva, Painting.

\footnotetext{
* Gustavo Quintero nació en 1985 en la pequeña isla de Puerto Rico, donde se crió y vivió hasta los 23 años. Se recibió de un Bachillerato en Artes con doble concentración en Literatura Comparada y Lenguas Extranjeras de la Universidad de Puerto Rico. Actualmente cursa una Maestría en Literaturas Españolas y Latinoamericanas en la Universidad de Buenos Aires. Lo puedes contactar en: labarbadecortazar@gmail.com
} 
Agua viva, novela publicada en 1973 es, entre otras cosas, una pequeña estrella fugaz dentro de la producción extensa de Clarice Lispector; una producción que incluye cerca de una decena de novelas, múltiples libros de cuentos, varios libros para niños, y siete años de crónicas para el Jornal do Brasil. La imagen de pequeña estrella fugaz le cae al dedillo porque para lo relativamente corta que es (apenas unas cien páginas), contiene en sí una amalgama sorprendente de estilos y técnicas que apuntan a una plena experimentación con y dentro del lenguaje y el medio de la escritura en sí. Es tan particular que la etiqueta de novela se le queda muy corta; a veces parece un epistolario, otras un diario y en algunos momentos aparenta disimular un flujo de conciencia. Es todos estos y ninguno a la vez.

Comencemos con esta cita tomada de Michel Seuphor, la cual sirve como epígrafe para la obra:

Debería existir una pintura totalmente libre de la dependencia de la figura -el objeto- que, como la música, no ilustra nada, no cuenta una historia y no lanza un mito. Esa pintura se contenta con evocar los reinos incomunicables del espíritu, donde el sueño se convierte en pensamiento, donde el trazo se convierte en existencia. 1

En varias ocasiones la voz narrativa en Agua viva menciona el deseo de poder escapar las limitaciones de la escritura para poder acceder a la pureza de emoción de la pintura, y en especial, de la música. ¿Por qué este deseo de trasgresión, de sobrepasar los límites? En este trabajo intentaremos dar cuenta de algunas técnicas utilizadas por Lispector para con este fin. Además veremos cómo en particular en esta obra la escritora brasileña se aproxima a una metodología que se asemeja más a la tradición plástica que a la tradición literaria. Como podemos observar, ya de partida el epígrafe nos da unas cuantas pistas de la dirección que va a tomar.

Una posible pintura totalmente libre de la dependencia de la figura. En la Lógica de la sensación, Deleuze nos describe la figura como "la forma sensible relacionada con la sensación, [es lo que] actúa inmediatamente sobre el sistema nervioso". ${ }^{2}$ Es decir, la figura está relacionada a una cierta materialidad, es un cuerpo o la forma que toma una sensación dada; es lo que podemos percibir por medio de los sentidos de primera instancia. Para

\footnotetext{
${ }^{1}$ SEUPHOR apud LISPECTOR. (epígrafe sin referencia completa en el texto de Clarice)
}

${ }^{2}$ DELEUZE, 2009, p. 41. 
definir una figura en el medio de la pintura se tiene que fabricar un color, que posteriormente servirá como medio de expresión del cuadro o el producto que salga de ese acto. Cuando entramos en otros registros artísticos estos factores pueden cambiar, por ejemplo, el caso de la música es muy diferente. Ahí el producto sensorial no tiene ninguna corporeidad; cuando escuchamos música el sonido como tal no está definido por ninguna forma, es la abstracción. Después que un instrumento ha creado un sonido no hay manera de percibirlo materialmente, es para todos los efectos, una sensación pura falta de un cuerpo, es presencia, existencia. La propuesta de Seuphor supone un componente que conlleva la eliminación de la figuración en la pintura para así liberarla y llevarla al campo del pensamiento puro.

En la historia del arte occidental, como regla general, hay una inclinación clara hacia la figuración (la narración, ilustración, el contar una historia); tanto así que estamos predispuestos como espectadores a que se nos provea una y cuando no la hay tendemos a inventarla por nuestra cuenta. Retomando el ejemplo de la música, podemos observar que la figuración bajo ningún precepto es una obligación dentro del medio. Es posible, como espectador, crearse una historia, pero no necesariamente es una que sea inherente a la pieza. Más que nada, tanto la música como esta posible pintura que imagina Seuphor lo que intentan es apuntar hacia un centro mucho más complejo e inasible que el de una simple narración. Al evocar los reinos incomunicables del espíritu hacen una apuesta por lo imposible.

Estilísticamente Agua viva se aleja considerablemente del campo narrativo tradicional. La novela, como género, acostumbra tener un hilo conductor que la atraviese, una historia, que aunque se disperse por continentes, personajes y épocas distintas, todavía mantenga dentro de su heterogeneidad un eje central; este no es el caso de nuestra novela. Como dice Nádia Battella Gotlib en relación a Un soplo de vida (referencia que bien podríamos aplicar en el caso de Agua viva y gran parte de la narrativa de Lispector): “De hecho, se nota una tendencia a alejarse cada vez más de lo figurativo, en la escritura, aproximándose más al ritmo y al sonido puros, desvinculados de compromisos con la línea continua de lo discursivo y de la historia". ${ }^{3}$ Como ya hemos mencionado anteriormente la

${ }^{3}$ GOTLIB, 2007, p. 523. 
novela en momentos aparenta formar parte de uno u otro género literario reconocible, $\mathrm{y}$ sin embargo nunca se estanca en ninguno de ellos, es puro movimiento, mutación. Por mencionar uno de los rasgos definitivos del estilo que demuestra lo alejada que está esta novela del género tradicional, es su estilo fragmentario, específicamente su división constante de los enunciados. Cada uno toma la forma de un corto párrafo, u oración, sincopada y no necesariamente lineal. En un momento la narradora puede estar confesando algún pensamiento, discurriendo unilateralmente con un hipotético amante, y en el próximo tener una iluminación total. A veces dilucida sobre la naturaleza de la pintura, o propone imágenes que serán seguidas por pequeños instantes de recolección o un salir de sí sin ninguna unidad lógica que las conecte. En otros casos es totalmente auto-crítica de lo que hace, lo que piensa y lo que escribe. Se podría argumentar que esta división de la novela en pequeños textos termina dándole un ritmo propio de lectura y de ferocidad intermitente que al final se rige por sus propias leyes internas. En otras palabras, para alejarse de lo figurativo Lispector desmonta la narrativa convencional; al no tener idea de lo que viene nos distendemos de nuestros hábitos normales de lectura y nos entregamos con menos prejuicios a la lectura.

En la escritura de Lispector existe un compromiso perenne con la palabra, aunque este compromiso aparente simultáneamente lindar en relación problemática. Para la autora escribir es una necesidad casi biológica, es su manera de revelar el mundo, y aún así, dentro de esta necesidad imperante, vemos que está siempre conciente de sus límites. "Escribir es intentar comprender, es intentar reproducir lo irreproducible, es sentir hasta el final el sentimiento que de otro modo permanecería apenas vago y sofocante". ${ }^{4}$ El escribir es un tipo de iluminación, un proceso de aclaración por medios externos. En el proceso de escritura la autora logra entenderse mejor, pondera gravemente sobre los temas que sólo lograría esbozar dentro de sí y logra darles una forma coherente. Al mismo tiempo paradójicamente está segura que es sólo un intento, es un devenir infinito y voluble de lo inalcanzable. Reproducir lo irreproducible, pequeña misión de vida que, como veremos posteriormente en la discusión, se logra iluminar hasta cierta medida.

${ }^{4}$ LISPECTOR apud GOTLIB, 2007, p.38. 
"Juro que este libro está construido sin palabras. Es una fotografía muda. Este libro es un silencio. Este libro es una pregunta". ${ }^{5}$ Tal parece que con esta cita tomada de $L a$ hora de la estrella Lispector nos estuviese expresando su propio deseo proyectado de Agua viva; una escritura desplegable, extendida, y evocante. Indicar, más que nombrar, es el método a seguir, a modo del Oráculo de Delfos. Después de la palabra yace el silencio, este es el único que podría dar una experiencia plena de lo que se quisiera siempre decir, de las esencias indecibles del ser; pero por el momento quedémonos en el lado de acá del silencio, que aunque constantemente es un gran horizonte en la escritura de Lispector, ahora mismo no nos concierne tanto.

Ahora bien, en la escritura el lenguaje y la palabra se convierten en la regla del juego. ¿Cómo hacer entonces para poder expresar lo inasible? Trampas del jugador compulsivo que se juega la vida en la escritura. Ya que el deseo apunta a lo inexpresable, en lugar de intentar capturar y fijar el lenguaje, la estrategia consiste en dejarlo respirar, permitir que él mismo nos lleve donde quiera y se ilumine un sentido propio por sí mismo. Según la narradora lo que hay que hacer es escribir la entrelínea:

Entonces escribir es la manera de quien usa la palabra como un cebo, la palabra que pesca lo que no es palabra. Cuando esa no-palabra - la entrelínea - muerde el cebo algo se ha escrito. Cuando se ha pescado la entrelínea, se puede con alivio tirar la palabra. Pero ahí termina la analogía: la no-palabra, al morder el cebo, lo ha incorporado. Lo que salva entonces es escribir distraídamente. 6

Una escritura que no dice lo que dice, sino lo que quisiera decir. La palabra se entiende aquí como límite y al mismo tiempo como potencialidad. Una escritura en condicional, de deseo disimulado con un velo, indirecta pero llena de intención.

Tomemos algunos ejemplos de Agua viva que sirvan para darle un poco de luz a este modo de escribir. "Lo que digo nunca es lo que digo sino otra cosa. Cuando digo 'aguas abundantes' estoy hablando de la fuerza del cuerpo en las aguas del mundo. Capta esa otra cosa de la que en realidad hablo porque yo misma no puedo". ${ }^{7}$ Como describe en la cita de la entrelínea, la palabra, usada como cebo, lleva a un tipo de metalenguaje que

\footnotetext{
${ }^{5}$ LISPECTOR, 2006, p. 18.

${ }^{6}$ LISPECTOR, 2008a, p. 23.

${ }^{7}$ Ibid., p. 32.
} 
produce una infinidad de campos de significación. Esta otra vida de la palabra la vuelve voluble pero indudablemente superior a la palabra inamovible; la enfrenta cara a cara con el discurso fijo o el logos en su estado más puro. En este sentido la narradora también se aleja de un acercamiento clásico de la palabra, al uso funcional y utilitario de la misma. Otro ejemplo sería este: “'Gozar de su levísima presencia' me da la sensación de haber escrito una frase completa porque dice exactamente lo que es: la levitación de los pájaros". 8 Para tomar prestado el título de un largometraje de la directora Isabel Coixet: ésta es la vida secreta de las palabras. Las palabras en la novela tienen una doble vida, un más allá que intenta asomarse por la esquina todo el tiempo. Lispector misma menciona: "Profundizo en las palabras como si pintase más que un objeto, su sombra". ${ }^{9}$ En lugar de encarar la palabra directamente, de lo que se trata aquí es de palpar los contornos, es decir, todo el universo que yace detrás ella. Este método resulta por momentos infinitamente superior, aunque sea por medio de desvíos de significación. Hagamos un experimento de aproximación: el logos propone la palabra silla y la fija tratando de hacer que la palabra silla corresponda a la silla que tenemos en frente, mientras que el acercamiento al entorno de la palabra silla, quisiera significar los cientos de años de vida del árbol y la laboriosa acción del carpintero que creó la obra de arte en que se convirtió.

Es muy notable que ella además expresa su falta de control sobre lo que hace, como si lo que dijera tomara vida propia, deviniera otro evento, la eterna mutación y movimiento. Toda Agua viva es un intentar nombrar que se reconoce de partida fallido, y sin embargo, es la estrategia perfecta: llegar a ser indirectamente, por medio de un pacto secreto con el Otro, un Otro que en este caso podría ser tanto el lector cual sea como el destinatario imaginario de las cartas. Este pacto se va renovando a través de toda la novela; desde un principio se propone por medio de un modo particular de escritura y de lectura. Un ejemplo de uno de los tantos modos es el escribir distraídamente de la cita de la entrelínea, pero posterguemos este punto por ahora, ya que posteriormente hablaremos de él al hablar del diagrama y el instante-ya. Al final, aún teniendo en cuenta los límites, se acomete la afrenta. Se escribe porque para la narradora no existe otro modo de rescatar ese más allá de la palabra: "Só quando falha a construção é que obtenho o que ela não

\footnotetext{
${ }^{8}$ Ibid., p. 54.

${ }^{9}$ LISPECTOR, 2008a, p. 16.
} 
conseguiu." ${ }^{10}$ Es el mejor intento de vida que se puede dar, fallido o no, algo se rescata de la experiencia.

"Este texto que te doy no es para ser visto de cerca, obtiene su secreta redondez antes invisible cuando se ve desde un avión en vuelo alto. Entonces se adivina el juego de las islas y se ven canales y mares". ${ }^{11}$ El escribir es un juego inacabable, es la búsqueda fructífera por la jungla del lenguaje. Para la narradora pues, todo decir se convierte en un mapa difuso, una dirección turbia, un señalar que se expande libremente y luego también como la música se convierte en presencia, ya que en esta entrelínea, en este hablar indirecto del lenguaje, lo que hay es.

El término presencia es de suma importancia acá, ¿qué es una presencia sino algo lleno de vida? Es un traer a la luz algo que parecía no estar allí. Si seguimos las célebres palabras de Paul Klee: "El arte no reproduce lo visible; vuelve visible" ${ }^{12}$, por medio de este indicar indirectamente, se posibilita, en parte, lo impensable: el artista descubre un mundo que para el resto no existía. En el griego clásico existe un término que está muy a fin con esta idea de Klee, el de alétheia. El término en sí se traduciría como una desocultación y ocultación a la vez, un desvelar momentáneo de una realidad fugaz. El artista, sea cual sea su medio, logra por instantes percibir estas presencias invisibles y las traduce en su creación. Rodeo de la palabra para llegar al latir del ser mismo, al centro de la vida, ésta es la palabra creadora. En parte podríamos decir que cuando Lispector afirma que escribe con el cuerpo, se está entregando toda al acto de la escritura, ella misma intenta vivir y producir dentro de esta palabra. Cada sílaba de cada palabra también es engendrar una vida, es la presencia misma. Una palabra que vive, respira y que es una con la experiencia de la narradora

Al mismo tiempo que se intenta crear la proyección de la entrelínea, la búsqueda de ese más allá de la palabra lleno de vida se refleja en el uso de algunas imágenes y un término que utiliza para describir la forma impersonal, el " $i t$ ” de las cosas. La primera y muy acertada imagen que usa es la de la gata que al tener su cría se come la placenta que la envuelve para poderla nutrir durante los días venideros. Este " $i t$ " es la vida misma, el ser-

\footnotetext{
${ }^{10}$ ANDRADE, 1998. Disponível em: <http://www.abralic.org/htm/revista/revista-04.jsp>.

${ }^{11}$ LISPECTOR, op. cit., p. 29.

${ }^{12}$ KLEE, 2007, p. 35.
} 
en-la-tierra de todos los entes. Esta pulsación de vida, esta inconciencia de ser y sobrevivir es para la narradora lo más cercano a existir. Otra imagen de animales que usa es la que titula la novela: la aguaviva o medusa. Este animal prehistórico, a veces un tanto amorfo, pero siempre deslumbrantemente bello, representaría de igual manera el estado originario. Para la narradora es central como acto poético el acercarse a esa vena viva de la vida.

En sus escritos sobre la pintura, Deleuze resalta un término que opina es el que une a todos los grandes pintores de la historia, y más lejos aún, funcionaría como el teorema central para una posible lógica de la pintura: el concepto de Diagrama. Iremos expandiendo este término para poder entender las implicaciones que tiene tanto en la pintura en general como en la escritura de Lispector, pero por ahora partimos desde lo más simple. Para comenzar por una definición material, el Diagrama sería (en el caso de Bacon) "el conjunto operatorio de líneas y zonas, de trazos y de manchas asignificantes y no representativos; y la operación del diagrama, su función, dice Bacon, es de sugerir". ${ }^{13}$ Para todos los efectos esta técnica sería la manera por la cual la pintura trata de eludir la trampa de la figuración. Decimos trata de eludir ya que como el mismo Bacon admite hay que mantener una figuración práctica para evitar caer en lo puramente abstracto. La función del Diagrama en la pintura es el permitir, como diría Bacon, que se introduzca en el cuadro, de golpe, una Zona de Sahara, o lo que Klee ha llamado el caos o el punto gris. La intención del Diagrama es crear un poco de catástrofe, un puente directo con el caos original. El artista intenta atravesar el cuadro, se pasea por el área indiscernible e inclasificable del caos, y trata de traer a relucir parte de su experiencia allí dentro. Resulta ser un arma de doble filo, ya que si la catástrofe toma control total y se desborda en todo el cuadro, se ha perdido la obra de arte, y esto Bacon lo especifica muy bien, es el peligro constante de la pintura. La clave aquí es el equilibrio, el acto de saber medir y controlar el caos. Acaso convendría relacionar esta idea de Bacon (y Klee, y otros) con la de Maurice Blanchot:

Hay, en la experiencia del arte y en la génesis de la obra, un momento donde ésta no es más que una violencia indistinta que tiende a abrirse y a cerrarse, tendente a exaltarse en un espacio que se abre y tendente a retirarse en la profundidad de la disimulación: la obra es entonces la intimidad en lucha de momentos irreconciliables e inseparables, comunicación desgarrada entre la medida de la obra que se hace poder y la desmedida de la obra que quiere la imposibilidad,

${ }^{13}$ DELEUZE, 2009, p. 103. 
entre la forma en que ella se recoge y lo ilimitado donde se rehúsa, entre la obra como comienzo y el origen a partir del cual ya nunca hay obra, donde reina el deshacimiento eterno. 14

Como peligro constante de pérdida, la obra de arte siempre se encuentra a merced del desvanecimiento, del devenir puro caos. Podemos inferir que la obra de arte también crea un lazo directo con el latir mismo de la vida. La palabra y la obra de arte son ambas un tipo de creación, forman una parte integral del ella, y la escritora lo que hace es servir de médium, de posibilitadora de esta existencia. Ella lucha constantemente entre lo que se hace poder y la imposibilidad que desea. Todo artista (por más que Deleuze o Bacon quieran pensar que esta relación es más directa en el medio de la pintura) tiene que enfrentarse a ese caos, al centro originario de la creación y rendir batalla con las fuerzas del universo hasta lograr procesarlas e insertarlas en la obra que será.

Podríamos hacer un cierto paralelo del concepto del Diagrama en Bacon con algunas técnicas de escritura que utiliza Lispector en Agua viva. En realidad es posible encontrar dos usos parecidos de éste en la novela, el único detalle es que para Lispector lo necesario es establecer puntos figurativos dentro de la selva no-figurativa. La parte nofigurativa, a grandes rasgos la parte más voluminosa de la narración, fluctúa incesantemente. Es por eso que consideraríamos el primer uso como un tipo de contraDiagrama, mientras que el segundo se asemeja al uso del mismo en Bacon. Ambos ejercen, a su manera, un efecto similar de sugestión.

Acá los fragmentos figurativos sirven para dar una corta estabilidad dentro de su monólogo o la marea de pensamiento: "De vez en cuando te daré una leve historia, un aria melódica y cantabile para romper este cuarteto de cuerda mío, una parte figurativa para abrir un claro en mi selva nutricia". ${ }^{15}$ Es posible sugerir que la escritura de Agua viva se regodea más dentro de la catástrofe, o el punto originario y aún así intenta, por medio de estos fragmentos, mantener un cierto orden o ritmo de lectura. Estos puntos de figuración son imprescindibles en el sentido que logran crear espacios para respirar dentro del texto. El ritmo sigue siendo, dentro de su lógica interna, un eje omnipresente de la narración.

\footnotetext{
${ }^{14}$ BLANCHOT, 2001, p. 41.

${ }^{15}$ LISPECTOR, 2008a, p. 36.
} 
Un buen ejemplo de lo que denominaríamos un contra-Diagrama es la imagen de la gruta. Hacia el principio de la novela la narradora rompe un fluir de ideas para caer en la imagen de la gruta, una imagen que hace poco tiempo solía pintar y ahora intenta describir por medio de la escritura. Este caso resulta esclarecedor en múltiples niveles, ya que sirve en primer lugar para explicar la relación y el método de escritura de la narradora vis-á-vis su modo de pintar. "Entro lentamente en la escritura como he entrado en la pintura". ${ }^{16}$ Luego continúa explicando casi como un riachuelo de descripción el dulce horror de la gruta. Para Lispector lo importante no es escribir en un plano realista la descripción de la gruta, sino que la raíz del problema yace en explicar el sentimiento o la sensación que se tiene al habitar la gruta. Porque en la novela la experiencia que se trata de manifestar y hacer transmitir es un habitar continuo, un habitar parecido al que experimentamos al estar frente una pintura. Es al parecer un habitar en conjunto, una experiencia compartida, ya que si nosotros estamos ahí dentro, ella está ahí presente con nosotros. La gruta se convierte en otro punto de origen, una fuente llena de vida y de horror. Y luego que nos suelta esta precaria imagen y corta al próximo corto enunciado volvemos a la marea de pensamiento, por decirlo así andamos a la deriva en el caos.

Otra instancia de esta técnica es la inserción de un texto previo de Lispector titulado De Natura Florum ${ }^{17}$ dentro de Agua viva. Nuevamente, luego de seguir navegando un tiempo la narradora decide hacer una parada en el islote de una imagen figurativa; en esta ocasión llegamos a una imagen a modo de diccionario botánico que nos muestra un sinnúmero de nombres de flores y sus más escondidas penas. Una a una va planteando su secreto dolor y una a una vamos entendiendo el secreto esbozado de la vida. Es otro momento iluminado del "it" de las cosas. Al plantar estas imágenes, la narradora continúa intentando llenar su texto de un cierto soplo de vida, un aliento que haga al texto respirar.

En el otro lado del espectro se sitúa el Diagrama á la Bacon, por decir así trazos geométricos de lenguaje, pero en este caso con la meta de disparar sílabas faltas de sentido. Quizás hace esto para acercarse a la vena de la musicalidad del lenguaje, para volver a destruir la institución del lenguaje. En ocasiones se regodea en el gusto de las palabras, casi como si se estuviese allegando más a la poesía: "Mi cuerpo incógnito te dice: dinosaurios,

\footnotetext{
${ }^{16}$ Ibid., p.17.

${ }^{17}$ Previamente publicado en LISPECTOR, 2008b, p. 258 o LISPECTOR, 2008a, p. 60, con diferencias.
} 
ictosaurios y pleosaurios, con un sentido tan sólo auditivo, sin que por eso se conviertan en paja seca, sino húmeda". ${ }^{18}$ Paja húmeda, llena de vida. Ritmo y música se unen en una para crear, por medio de estos trazos asignificantes, otra sugestión. O ésta oración maravillosa: "Entiéndeme: te escribo una onomatopeya, una convulsión del lenguaje. Te transmito no una historia sino sólo palabras que viven del sonido. Te digo por ejemplo: 'Tronco lujurioso"". ${ }^{19}$ En un juego constante con el lenguaje, aquí volvemos nuevamente a ceder un poco de terreno frente a la entrelínea. Lo que se dice no es lo que se dice, sino que apunta a otro campo totalmente explosivo, un big bang de sentidos.

Ya que vamos llegando gradualmente al centro vivo de las imágenes, a las presencias o lo que yace detrás de la entrelínea, quizás sea bueno entrelazarlo con una cita de uno de los grandes maestros de la pintura moderna. Mejor dicho, tomemos unas palabras que cita Deleuze de un libro de Gasquet. En su libro, Gasquet reconstruye algunas de sus conversaciones con Cézanne y en una, supuestamente, el maestro pintor dice: "Quisiera pintar el espacio y el tiempo para que devengan las formas de la sensibilidad de los colores, porque a veces imagino los colores como grandes entidades noumenales, ideas vivas, seres de razón pura". ${ }^{20}$ Volvemos elípticamente a caer en la idea de la sensación como la materialidad de la idea. Pero este sostén físico (en el caso de Cézanne, como explica acá, el color) tiene detrás de él la esencia misma de las cosas, un latir o una presencia de vida. Ahora, él especifica muy bien una serie de factores que le ayudan a llegar allí: el espacio y el tiempo. Esta cadena de factores va creando el andamiaje de lo sensible, son por así decirlo su arquitectura.

Acaso el mayor acto trasgresor de Lispector en Agua viva sea querer hacer lo que Deleuze denomina pintar las fuerzas. ¿Cuál de todas? El tiempo. El andamiaje de la sensibilidad de los colores se convierte en la novela en un intentar captar lo que es probablemente una de las fuerzas invisibles más importantes que actúan sobre el cuerpo humano a través de toda su vida. Es un hecho, estamos regidos por el tiempo incesantemente desde el momento que nacemos hasta el último microsegundo de vida restante en nuestro cuerpo. Siempre está presente, y a veces, en ocasiones nos olvidamos

\footnotetext{
${ }^{18}$ LISPECTOR, 2008a, p 14.

${ }^{19}$ LISPECTOR, 2008a, p. 30.

${ }^{20}$ DELEUZE, 2007, p. 28;
} 
que estamos a su merced. Desde el instante que nacemos estamos dirigidos vertiginosamente hacia la muerte por la línea del tiempo. Y aún así no es un factor que podamos visualizar, no tiene ninguna materialidad. Es una esencia invisible, incorpórea, pero omnipresente. Habitamos el tiempo, y por medio de él, de su constante vibración ejercida sobre nosotros, nos convertimos en un devenir constante. Siempre podemos volver a Klee: el verdadero arte vuelve visible. El arte ilumina esa presencia etérea que siempre estuvo ahí y nunca logramos percibir. La pregunta entonces se convierte en cómo hacer esto posible desde la literatura, específicamente, cómo hacer esta experiencia transmisible por medio de la escritura y la lectura.

Desde el arranque el instante-ya es una preocupación que recorre todo el texto de Agua viva. El instante-ya, podríamos decir es un poco más preciso que un instante cualquiera, es una conciencia de un tiempo presente, es captar el momento justo al mismo tiempo que pasa. En el inicio la narradora se lo propone como punto de partida para la novela:

Te digo: estoy intentando captar la cuarta dimensión del instante ya, que tan fugitivo ya no existe porque se ha convertido en un nuevo instante-ya que ahora tampoco existe $[\ldots]$ Y quiero capturar el presente que, por su propia naturaleza me está prohibido, el presente se me escapa, la actualidad huye, la actualidad soy yo siempre en presente. 21

Un perseguir el tiempo escurridizo, la fuerza en eterna mutación. Para la narradora el acto transgresivo en sí es un atentado contra lo imposible. El intentar captar el presente, la simultaneidad del tiempo que en sí le es vedado al humano, funciona como propuesta detonadora de la narración. De nuevo volvemos a un desvelamiento de una esencia, el presente es ser en su estado más puro, cuando se es se está en el campo del “it”. El presente se entiende aquí como una esencia voluble y al mismo tiempo lúdica, hay que jugar a perseguirla, esencia infinitamente renovable. Eso, sin decir que al mismo tiempo que se persigue este presente lo que se busca es un encuentro con sí misma, es una investigación del ser.

${ }^{21}$ LISPECTOR, 2008a, p. 11. 
"Ahora voy a escribir al albur de la mano; no intervengo en lo que ella escribe. Ésa es la manera de que no haya un desfase entre el instante y yo; actuar en el meollo del mismo instante". ${ }^{22}$ Este parece ser en momentos el acercamiento más próximo que la narradora puede hacer con el instante, convertirse en una con el presente. No obstante, hay una conciencia plena de que la imposibilidad de su misión. El instante-ya como propuesta es un maravilloso punto de partida que lleva a otra serie de descubrimientos, pero tiene sus limitaciones: "siempre hay algún desfase". ${ }^{23}$ Por más que se le de el poder a la mano y a la escritura de ser completamente autosuficientes, siempre hay un período de separación entre el germinar de la idea y el acto de escribirla.

Y aún así, el modo en que está escrita la novela crea una cierta ilusión de inmediatez: por momentos, mientras leemos, parecería que la palabra se extrae con vida del papel; es como si justo cuando uno lee está recibiendo el pensamiento directo de la narradora, como si simultáneamente al pensar ella lo estuviéramos leyendo nosotros, o como si nos lo leyera ella misma: otro de los beneficios del mélange genérico de Agua viva. Puede ser que esto tenga que ver con el carácter pseudo-epistolar de la novela, ya que por momentos parecería que estamos en el confesionario de la narradora, escuchando su propia voz. Esta palabra resuena con energía, no es la palabra muerta y estática en el papel, sino una palabra viviente. "Voy a coger el presente en cada frase que muere" ${ }^{24}$ y luego continúa haciendo un listado de lo que piensa y cómo actúa: se va, vuelve; todo ayuda a construir la ilusión de la inmediatez, de alguna manera ese presente distante de la escritura se ha convertido también en nuestro propio presente de lectura.

El tiempo al que se quiere acercar la narradora es un ahora; por decirlo así es un presente activo, que late y está lleno de vida. Quizás la mejor manera de visualizar esta conexión entre el instante-ya y el "it" sea esta imagen: "Coger un pájaro en la palma medio cerrada de la mano es terrible, es como si tuviese los instantes trémulos en la mano". ${ }^{25}$ Dulce terror como el de la gruta, lo que pasa es que el ser humano ha perdido ya una cierta conexión con el núcleo originario, tanto así que cuando se acerca a él le causa vértigo. Y a

\footnotetext{
${ }^{22}$ Ibid., p. 57.

${ }^{23}$ LISPECTOR, 2008a, p. 57.

${ }^{24}$ Ibid., p. 88.

${ }^{25}$ Ibid., p.53.
} 
la misma vez es exactamente lo que la narradora se propone hacer, tender puentes con el origen de la vida misma.

En conclusión, en Agua viva, Clarice Lispector subvierte gran parte de la tradición literaria. Por medio de una serie de técnicas narrativas que aquí hemos discutido se aleja de una narración clásica. Tomando las pautas de un epílogo de Steuphor intenta evocar los reinos incomunicables del espiritu, hazaña hecha aún más extraordinaria cuándo consideramos la condensación de ideas que manifiesta el texto. La novela hace una apuesta por el universo variable de la sensación, nos invita a poblar su marea de sentidos y a separarnos de nuestro modo usual de lectura. Al sugerir un distanciamiento de la figuración la novela adquiere un ritmo propio que le permite a la narradora tanto mostrar la lucha interna de ideas, como llegar a una serie de registros no fácilmente logrado por muchos. En ella la palabra adquiere un peso sin precedentes que cumple una plétora de funciones. Por un lado adquiere una ambivalencia propia de la entrelínea, una explosión de sentidos, horizonte de la significación. En esencia lo que más claramente presenciamos es un captar las presencias que siempre estuvieron ahí pero nunca pudimos ver. En ese sentido el develar que se posibilita por la escritura, al igual que cualquier otro medio artístico, se convierte en un puente directo con el caos originario y el lenguaje es su clave. Como Lispector expresó en alguna vez en su columna del Jornal do Brasil: La palabra es mi dominio sobre el mundo. ${ }^{26}$ Palabra del presente, explosiva y voluble, palabra que pinta las fuerzas.

${ }^{26}$ LISPECTOR, 2008a, p. 80. 


\section{REFERÊNCIAS}

ANDRADE, Ana Luiza. Saturno Devorador da Modernidade: Imagens/Sensações. Revista Brasileira de Literatura Comparada, ABRALIC/Florianópolis, n. 4, 1998. Disponível em: $<$ http://www.abralic.org/htm/revista/revista-04.jsp>.

BLANCHOT, Maurice. La bestia de Lascaux. In: . La bestia de Lascaux. El último en hablar. Trad. Alberto Ruiz de Samaniego. España: Tecnos, 2001.

DELEUZE, Gilles. Francis Bacon: Lógica de la sensación. Trad. Isidro Herrera. Madrid: Arena Libros, 2009.

. Pintura: El concepto de diagrama. Buenos Aires: Cactus, 2007.

GOTLIB, Nádia Battella. Clarice: Una vida que se cuenta. Trad. Álvaro Abós. Buenos Aires: Adriana Hidalgo, 2007.

KLEE, Paul. Teoría del arte moderno. Trad. Pablo Ires. Buenos Aires: Cactus, 2007.

LISPECTOR, Clarice. La hora de la estrella. Trad. Ana Poljak. Madrid: Siruela, 2006. . Água viva. Trad. Elena Losada. Madrid: Siruela, 2008a.

2008b.

. Revelación de un mundo. Trad. Amalia Sato. Buenos Aires: Adriana Hidalgo, 